\title{
Changes in gut microbiota of alloxan-induced diabetic rats in response to orally administered combined aqueous extracts of olive leaves and ginger
}

\author{
Shatha Alshaer ${ }^{1}$, Feras Darwish El-Hajji², Reem Abu-Tayeh³, Iman Basheti², Mohammad A. A. Al-Najjar ${ }^{1 *}$ \\ ${ }^{1}$ Pharmaceutical Sciences and Pharmaceutics Department, Applied Science Private University, Amman, Jordan. \\ ${ }^{2}$ Clinical Pharmacy and Therapeutics Department, Applied Science Private University, Amman, Jordan. \\ ${ }^{3}$ Pharmaceutical Chemistry and Pharmacognosy Department, Applied Science Private University, Amman, Jordan.
}

\begin{tabular}{l}
\hline ARTICLE INFO \\
\hline Received on: $28 / 07 / 2021$ \\
Accepted on: 11/11/2021 \\
Available Online: 05/03/2022 \\
\hline Key words: \\
Diabetes mellites, gut \\
microbiota, olive leaves \\
extracts, ginger rhizome extract, \\
prebiotic effect, short-chain fatty \\
acid production.
\end{tabular}

\section{INTRODUCTION}

Diabetes mellitus (DM) is one of the oldest diseases known to humans. It was documented in the ancient Egyptian civilization 3,000 years ago (Baynest, 2015). DM is a chronic metabolic disease clinically characterized by elevated blood glucose due to insulin insufficiency or lack of efficacy (Chaudhury et al., 2017). Unfortunately, when blood glucose concentrations are raised in the tissues, complications arise, including macrovascular, microvascular, and neuropathic ailments (Weiss et al., 2000). It is

\section{*Corresponding Author}

Mohammad A. A. Al-Najjar, Pharmaceutical Sciences and Pharmaceutics Department, Applied Science Private University, Amman, Jordan. Email: moh_alnajjar@asu.edu,jo expected that by the year 2045 there will be more than 600 million diabetic patients worldwide (Yaribeygi et al., 2016). Growing evidence indicates that modifications in gut microbiota are related to several metabolic diseases, such as obesity and DM (Aw and Fukuda, 2018). Additionally, the relative abundance of several gut microbes was noted to have changed along with the development of DM (Zhang et al., 2018). The fecal bacterial composition investigated in healthy and diabetic volunteers indicated that a relative abundance of Prevotella was significantly reduced in a diabetic group compared to a healthy group (Tremaroli and Bäckhed, 2012), while a diminished Firmicutes/Bacteroidetes ratio was found in children with DM type 1 (Aw and Fukuda, 2018).

Polyphenols are abundant in the plant kingdom. Polyphenols are compounds containing one or more aromatic rings with at least one hydroxyl group attached. These polyphenols range from small and single-aromatic-ringed compounds to those with 
Table 1. In vivo, the experiment groups and the treatments that were used.

\begin{tabular}{|c|c|c|c|c|}
\hline Groups numbers & Status & Treatments & $\begin{array}{l}\text { Total number } \\
\text { of rats }\end{array}$ & $\begin{array}{c}\text { Number of rats used for } \\
\text { gut microbiota }\end{array}$ \\
\hline Group I & Diabetic & $6 \mathrm{IU} / \mathrm{kg}$ insulin & 7 & 2 \\
\hline Group II & Diabetic & $\begin{array}{c}6 \mathrm{IU} / \mathrm{kg} \text { insulin }+500 \mathrm{mg} / \mathrm{kg} \text { olive leaves extract }+ \\
500 \mathrm{mg} / \mathrm{kg} \text { ginger rhizome extract }\end{array}$ & 7 & 2 \\
\hline Group III & Diabetic & $\begin{array}{c}500 \mathrm{mg} / \mathrm{kg} \text { olive leaves extract }+500 \mathrm{mg} / \mathrm{kg} \text { ginger } \\
\text { rhizome extract }\end{array}$ & 6 & 2 \\
\hline Group IV & Healthy & $\begin{array}{c}500 \mathrm{mg} / \mathrm{kg} \text { olive leaves extract }+500 \mathrm{mg} / \mathrm{kg} \text { ginger } \\
\text { rhizome extract }\end{array}$ & 6 & 2 \\
\hline
\end{tabular}

more than 110 aromatic rings (Bi et al., 2017). These complexes offer aroma and pigment to crops and can also influence human health, due to their antioxidant properties, free-radical scavenging activity, and antimicrobial properties (Chodak, 2012). In the last few years, a polyphenol-rich diet has become a popular trend due to its benefits in fighting many diseases like DM. Moreover, several in vitro studies conducted on animals showed that these polyphenols can inhibit the growth of microorganisms such as bacteria (Chodak, 2012; Dueñas et al., 2015b). Polyphenols also showed a positive effect on human gut microbiota, where Prevotella significantly increased in healthy volunteers who consumed red wine polyphenols daily for 4 weeks (Queipo-Ortuno et al., 2012).

The olive tree (Olea europaea) is one of the more famous plants that have commonly been used as a traditional treatment for combating diseases, due to the fact that they possess abundant polyphenolic compounds (i.e., more than $40 \mathrm{~g} / \mathrm{kg}$ of dry tissue) (Afify et al., 2018). Historically, olive leaves have been largely used as a treatment for fever and other diseases, such as malaria in Europe and Mediterranean countries (Ghanbari et al., 2012). Many experiments have shown that oleuropein, the most potent polyphenol in olive leaves, demonstrates an extensive range of beneficial properties such as anti-inflammatory, antimicrobial, and antidiabetic agents (Özcan and Matthäus, 2017). Another famous and widely used plant is the ginger rhizome (Zingiber officinale), which is rich in polyphenolic compounds like gingerol (Butt and Sultan, 2011). The quantity of polyphenolic compounds in the rhizome is $3.17 \mathrm{mg} / \mathrm{g}$ (Embuscado, 2015). It is a valuable hot spice with numerous health benefits in most parts of the world. The rhizomes of ginger have traditionally been used for the treatment of diabetes, gingivitis, and infectious diseases (Jacob and Narendhirakannan, 2019).

Food and medicines have a significant influence on gut microbiota compositions and their roles (Aw and Fukuda, 2018). Thus, when using plants as a natural therapy, they may alter gut microbiota and their functions in the healthy and diabetic states. The shift in gut microbiota due to the aqueous extract of the combined mixture of olive leaves and ginger rhizome has not been covered comprehensively in the studies so far. Hence, this study investigated the effects of orally ingesting the combined aqueous extracts of olive leaves and ginger, both with or without insulin, on changing gut microbiota in healthy and in alloxan-induced diabetic rats. The treatment was conducted for 1 week to evaluate the effect of this herbal extract on promoting intestinal health by maintaining gut microbial balance through stimulating the growth of beneficial bacteria and the inhibition of pathogenic bacteria.

\section{MATERIALS AND METHODS}

All the experimental treatments in this study were ethically approved by the Institutional Review Board Committee for the field of Clinical Pharmacy and Pharmacy Practice at the Applied Science Private University (ASU), Faculty of Pharmacy (Approval No. 2020-PHA-10).

\section{EXPERIMENTAL ANIMALS AND EXPERIMENTAL DESIGN}

Twenty-six Wistar rats of either sex weighing between 150 and $175 \mathrm{~g}$ were used. The rats were divided randomly before the experiment into four groups according to Table 1 . The rats of each group were retained in two separate standard cages (with wooden chips as bedding) to avoid gestation. All the groups were kept in a stable environment under a 12/12 hour, light-dark cycle, in room temperature conditions $\left(25^{\circ} \mathrm{C} / 50 \%-60 \%\right.$ relative humidity), and a stream of continuous fresh air was available to accomplish all required environmental conditions. The rats were kept in these conditions for 2 weeks to adapt. They had free access to water and were fed with standard food.

\section{PREPARATION OF EXTRACTS}

Fresh leaves of olive (Olea europaea) were collected by handpicking in the middle of October 2019 from a specific olive tree plantation farm in Jerash, Jordan. Fresh ginger rhizomes (Z. officinale) were bought from the local market in the Amman region of Jordan.

The extracts in this study were prepared in the same simple traditional way as that of homemade preparation methods in local communities. The extracts were freshly prepared every other day to preserve freshness and stability. Aqueous olive leaves extraction was based on the methods described by Zoair (2014) and Abu-Zaiton and Abu-Albasal (2012), with slight modifications. Ten grams of clean (washed) olive leaves was weighed, pulverized in an electric blender (Model No. MX-GX1521, Panasonic Taiwan Co., Ltd., Taiwan), and then soaked in $100 \mathrm{ml}$ distilled water at room temperature for 24 hours. Afterward, the whole mixture was boiled for 3 minutes to obtain a final concentration of 100 $\mathrm{mg} / \mathrm{ml}$ after the filtration process (Abu-Zaiton and Abu-Albasal, 2012; Zoair, 2014). The aqueous extraction method of the ginger rhizomes was adopted from the Abdulrazaq et al. (2012) method, with a few modifications. Briefly, $10 \mathrm{~g}$ of fresh ginger rhizomes was crushed and then soaked in $100 \mathrm{ml}$ distilled water for 24 hours at room temperature. Then, they were later filtered by cotton wool (Model No. FL8008, Forlong Medical Co., Ltd., Wuxi 
Jiangsu, China) to achieve the final concentration of $100 \mathrm{mg} / \mathrm{ml}$ (Abdulrazaq et al., 2012). Finally, the two olive leaves and ginger rhizomes extracts were stored separately in tightly closed amber glass bottles in the fridge $\left(\right.$ at $2^{\circ} \mathrm{C}-8^{\circ} \mathrm{C}$ ) until they were needed.

\section{INDUCTION OF DIABETES}

The rats were fasted for 16 hours, and then their blood glucose levels were measured before the induction of diabetes (Kumbhare and Sivakumar, 2019). DM was induced in the rats by a single-dose intraperitoneal injection of alloxan monohydrate (purchased from Santa Cruz Biotechnology, California, USA). A dose of $150 \mathrm{mg} / \mathrm{kg}$ (body weight) alloxan monohydrate was prepared in a sterile, cold saline solution $(0.9 \%$ sodium chloride, $\mathrm{pH} 7$ ) immediately before use (Aluwong et al., 2016). The rats were treated with $5 \%$ glucose solution $(1-2 \mathrm{ml})$ gavage after 30 minutes of injection and were then given free access to food. They were kept on $5 \%$ glucose solution bottles for 24 hours in their cages to prevent fetal hypoglycemia due to the massive release of insulin from injured pancreatic $\beta$-cells (Abu-Zaiton and AbuAlbasal, 2012). After 4 days of alloxan injection, blood was collected from overnight fasted rats, and the fasting blood sugar was estimated by using the Accu-Chek glucometer (Performa, Roche, Penzberg, Germany). The complete development of DM was maintained when the fasting blood glucose levels reached $\geq 1$.5-fold the baseline reading (Kumbhare and Sivakumar, 2019).

All extract treatments were administered orally once a day, and the insulin (Mixtard 30 pre-filled insulin suspension for injection obtained from Novo Nordisk, Bagsværd, Denmark) was given at a $6 \mathrm{IU} / \mathrm{kg}$ single dose subcutaneously once a day (Table 1).

\section{SAMPLES COLLECTION, DNA SEQUENCING, AND DATA ANALYSIS}

Samples of feces from random rats were freshly collected in a sterile plastic Eppendorf centrifuge tube (Model No. TUBE170-C, ExtraGene, Inc., Taiwan) on day 0 (d0) (before treatment). Fecal samples were again collected from the rats after the first week of treatment (d7). After each collection, the fecal samples were directly frozen at $-80^{\circ} \mathrm{C}$ and retained until the gut bacteria composition was analyzed (Djurasevic et al., 2018). The DNA was extracted from the fecal samples using a dedicated DNA extraction QIAamp ${ }^{\circledR}$ DNA Mini Kit protocol (purchased from QIAGEN, Germany). The extracted DNA was sent to the Molecular Research Lab (www. mrdnalab.com, MR DNA, Shallowater, TX) for sequencing and data processing. Polymerase chain reaction (PCR) amplification of the V4 variable region of the 16s rRNA gene was conducted using the primers ill27Fmod (AGRGTTTGATCMTGGCTCAG)/ill519Rmod (GTNTTACNGCGGCKGCTG) with a barcode on the forward primer. The PCR products were checked in $2 \%$ agarose gel to determine the success of amplification, followed by pooling the purified PCR product to be sequenced using Illumina on a MiSeq following the manufacturer's guidelines. Sequencing data were analyzed using the MR DNA analysis pipeline (MR DNA, Shallowater, TX, USA). Briefly, the sequences were joined and depleted of barcodes, and then sequences $<150 \mathrm{bp}$ were removed, and sequences with ambiguous base calls were neglected. Sequences were denoised, operational taxonomic units (OTUs) generated, and chimeras removed. Final OTUs were taxonomically classified using BLASTN against a curated database derived from Ribosomal Database Project II and National Center for Biotechnology Information (www.ncbi.nlm.nih. gov, http://rdp.cme.msu.edu). The alpha diversity index, namely, Shannon index $H$, was calculated in the PAleontological STatistics program for data analysis version 4.02 , after filtering out the readings with the relative abundance of $<1 \%$. The Shannon index varies from 0 for communities with only a single taxon to high values for communities with many taxa.

\section{RESULTS}

\section{Development of DM and the effect of the extracts' combination}

The fasting blood glucose levels were elevated at least four times for the three groups treated with alloxan after 4 days of the injection, which were compared with baseline fasting blood glucose for each group (Table 2). This increase in the blood glucose levels indicates the development of DM.

\section{GUT MICROBIOTA IDENTITY ANALYSIS}

\section{Biodiversity, richness, and composition of gut microbiota}

The investigated samples from all the groups at $\mathrm{d} 0$ showed an extremely similar Shannon index of $0.85 \pm 0.03$, which varied significantly based on the extract mixture that was used. For example, it was the highest (highest biodiversity) for the group III diabetic rats after 1 week of administering the combination of olive leaves extract and ginger rhizome extract treatment $(H=1.14)$. On the other hand, it was the lowest for group I, i.e., diabetic rats treated with $6 \mathrm{IU} / \mathrm{kg}$ insulin only $(H=0.80)$ (Table 3$)$. Richness was highest after the treatment for group II and for the members of

Table 2. Comparative mean fasting blood glucose levels $(\mathrm{mg} / \mathrm{dl})$ in the studied groups, initially (before alloxan treatment, initial), after 4 days of the treatment (d4), and 1 week after alloxan treatment (d7).

\begin{tabular}{|c|c|c|c|}
\hline The groups & $\begin{array}{l}\text { Glucose } \\
\text { (initial) } \mathrm{mg} / \mathrm{dl}\end{array}$ & $\begin{array}{c}\text { Glucose (d4) } \\
\mathrm{mg} / \mathrm{dl}\end{array}$ & $\begin{array}{l}\text { Glucose (d7) } \\
\text { mg/dl }\end{array}$ \\
\hline Group I: diabetic (with $6 \mathrm{IU} / \mathrm{kg}$ insulin only) & $66.3( \pm 3.7)$ & $282.0( \pm 148.0)$ & $132.3( \pm 103.7)$ \\
\hline $\begin{array}{c}\text { Group II: diabetic (with } 6 \mathrm{IU} / \mathrm{kg} \text { insulin }+500 \mathrm{mg} / \mathrm{kg} \text { olive leaves } \\
\text { extract }+500 \mathrm{mg} / \mathrm{kg} \text { ginger rhizome extract) }\end{array}$ & $66.3( \pm 3.7)$ & $302.9( \pm 219.4)$ & $144.4( \pm 102.2)$ \\
\hline $\begin{array}{c}\text { Group III: diabetic (with } 500 \mathrm{mg} / \mathrm{kg} \text { olive leaves extract }+500 \mathrm{mg} / \mathrm{kg} \\
\text { ginger rhizome extract) }\end{array}$ & $65.7( \pm 3.7)$ & $292.3( \pm 214.9)$ & $495.0( \pm 105.6)$ \\
\hline $\begin{array}{c}\text { Group IV: healthy (with } 500 \mathrm{mg} / \mathrm{kg} \text { olive leaves extract }+500 \mathrm{mg} / \mathrm{kg} \\
\text { ginger rhizome extract) }\end{array}$ & $62.5( \pm 6.5)$ & $85.2( \pm 8.5)$ & $66.3( \pm 9.5)$ \\
\hline
\end{tabular}

The values represent the mean and the standard deviation $( \pm \mathrm{SD})$. 
Table 3. Alpha biodiversity (richness and Shannon index) of the different members from the studied groups. Samples were freshly collected from day 0 before giving anything $(\mathrm{d} 0)$, and the fecal samples were collected again from the same rats after the first week of treatment (d7).

\begin{tabular}{cccccc}
\hline \multirow{2}{*}{ Time } & No. OTUs & No. taxa & $\begin{array}{c}\text { Shannon (diversity } \\
(\boldsymbol{H}) \text { ) }\end{array}$ & Chao_1 (richness) \\
\hline \multirow{2}{*}{ Group I } & Initial (d0) & 25,292 & 14 & 0.87 & 12.0 \\
& Final (d7) & 24,678 & 17 & 0.80 & 14.5 \\
\multirow{3}{*}{ Group II } & Initial (d0) & 23,547 & 14 & 0.81 & 16.3 \\
& Final (d7) & 21,966 & 19 & 0.91 & 19.0 \\
\multirow{3}{*}{ Group III } & Initial (d0) & 25,216 & 17 & 0.84 & 15.0 \\
& Final (d7) & 24,959 & 15 & 1.14 & 17.5 \\
& Initial (d0) & 22,215 & 19 & 0.87 & 13.0 \\
\hline
\end{tabular}

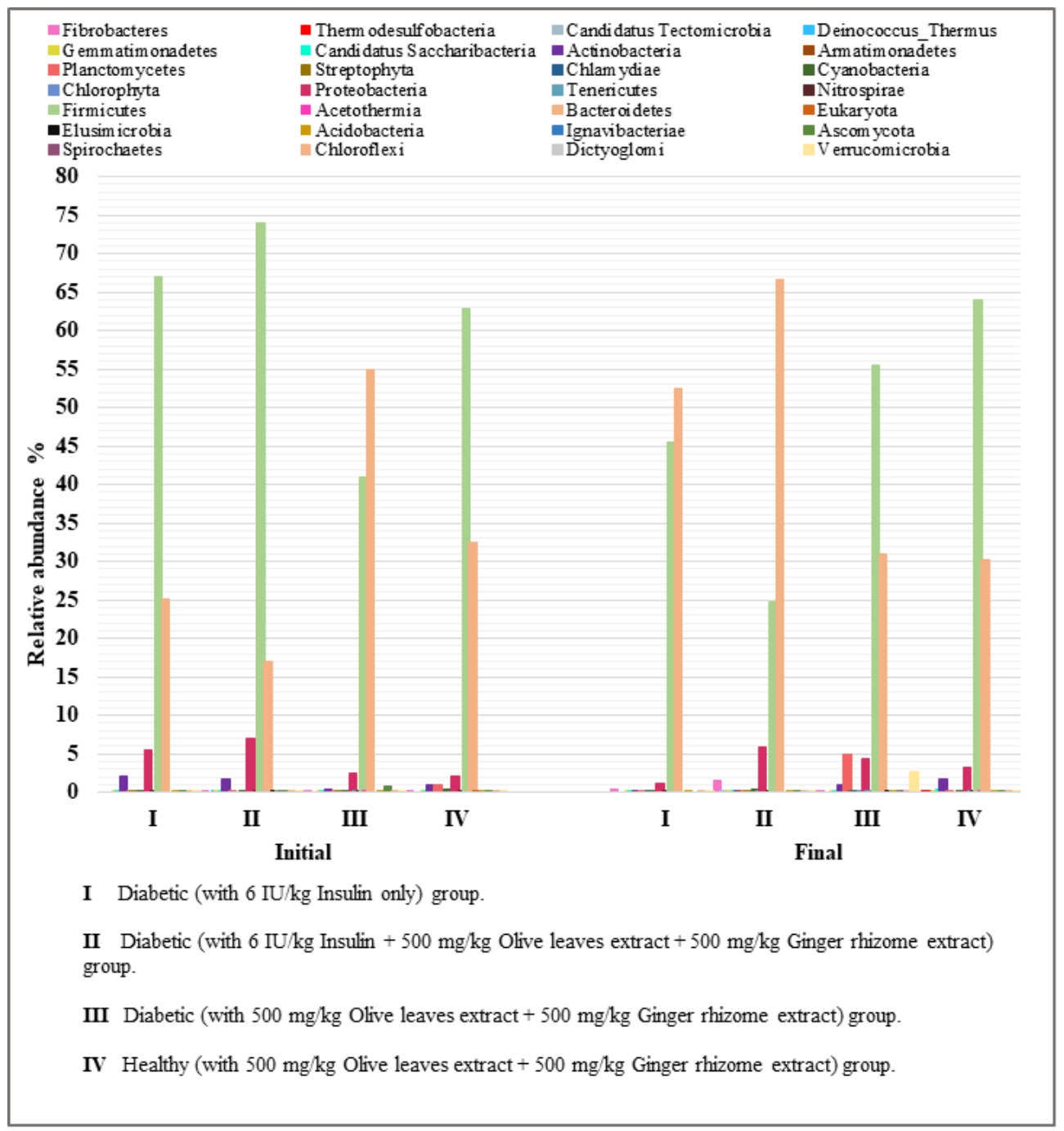

Figure 1. Relative abundance of all phyla in fecal samples. Samples of feces were freshly collected from day 0 before giving anything (Initial), and the fecal samples were collected again from the same rats after the first week of treatment (Final).

the healthy group, given the combination of the aqueous extracts (control group, IV), suggesting a positive effect of the combined extracts on increasing richness (represented by the Chao-1 index).

The total number of the detected bacterial phyla was 28; however, when considering those with relative abundances that are $\geq 1 \%$ among the four studied groups, the number decreased dramatically to three phyla, which are Firmicutes, Bacteroidetes, and Proteobacteria (Fig. 1). The relative abundance of Firmicutes ranges between $24.8 \%$ and $74.0 \%$, followed by that of Bacteroidetes $(17.0 \%-66.7 \%)$, and then Proteobacteria $(1.2 \%-6.9 \%)$. At $\mathrm{d} 0$ (i.e., before treatment), group II displayed the highest relative abundance of Firmicutes $(74.0 \%)$ and Proteobacteria $(6.9 \%)$ and 


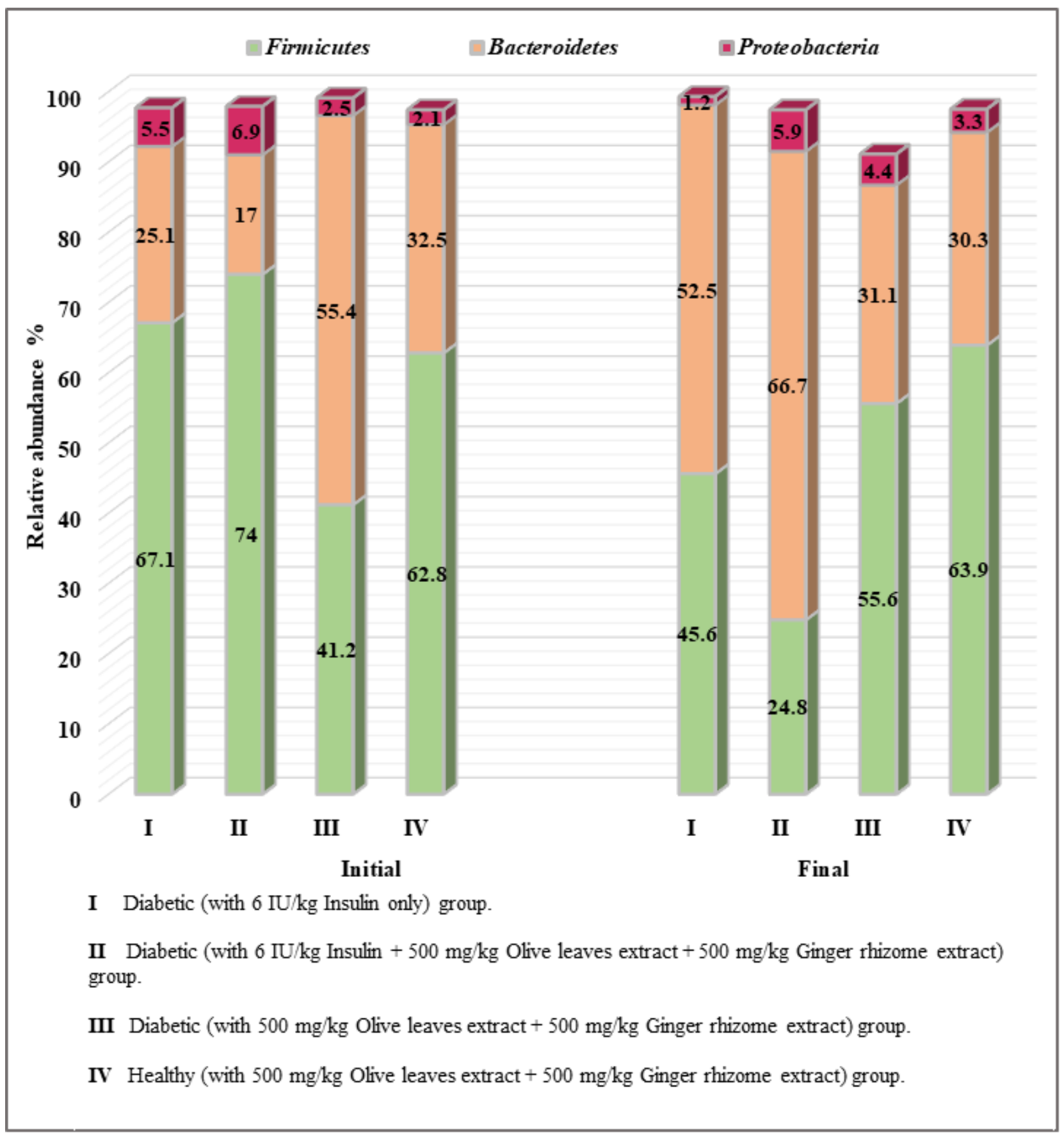

Figure 2. Relative abundance of the most abundant phyla in the fecal samples. Samples of feces were freshly collected from day 0 before giving anything (Initial), and the fecal samples were collected again from the same rats after the first week of treatment (Final).

the least abundance of Bacteroidetes (17\%). Group II also had the highest relative abundance of Bacteroidetes (66.7\%) after 1-week treatment (with $6 \mathrm{IU} / \mathrm{kg}$ insulin and the extracts' combination) and the least relative abundance of Firmicutes (24.8\%). Finally, the least abundance of Proteobacteria (1.2\%) after 1-week treatment was in group I (Fig. 2).

\section{Relative abundance of phyla in fecal samples}

The 1-week administration of treatments to the rats led to reduced Firmicutes and Proteobacteria in groups I and II and increased Bacteroidetes among the groups. However, alternate results were found in the gut microbiota of groups III and IV, where Firmicutes and Proteobacteria were elevated and Bacteroidetes reduced after 1-week treatment (Fig. 2).

The treatments affected the Firmicutes/Bacteroidetes ratio in both nondiabetic and diabetic animals. There was an increased Firmicutes/Bacteroidetes ratio observed in the gut microbiota of groups III and IV (Fig. 3).

Relative abundance of genera in the fecal samples

Most of the gut microbiota belonging to Firmicutes (including Lactobacillus and Clostridium genera) and 


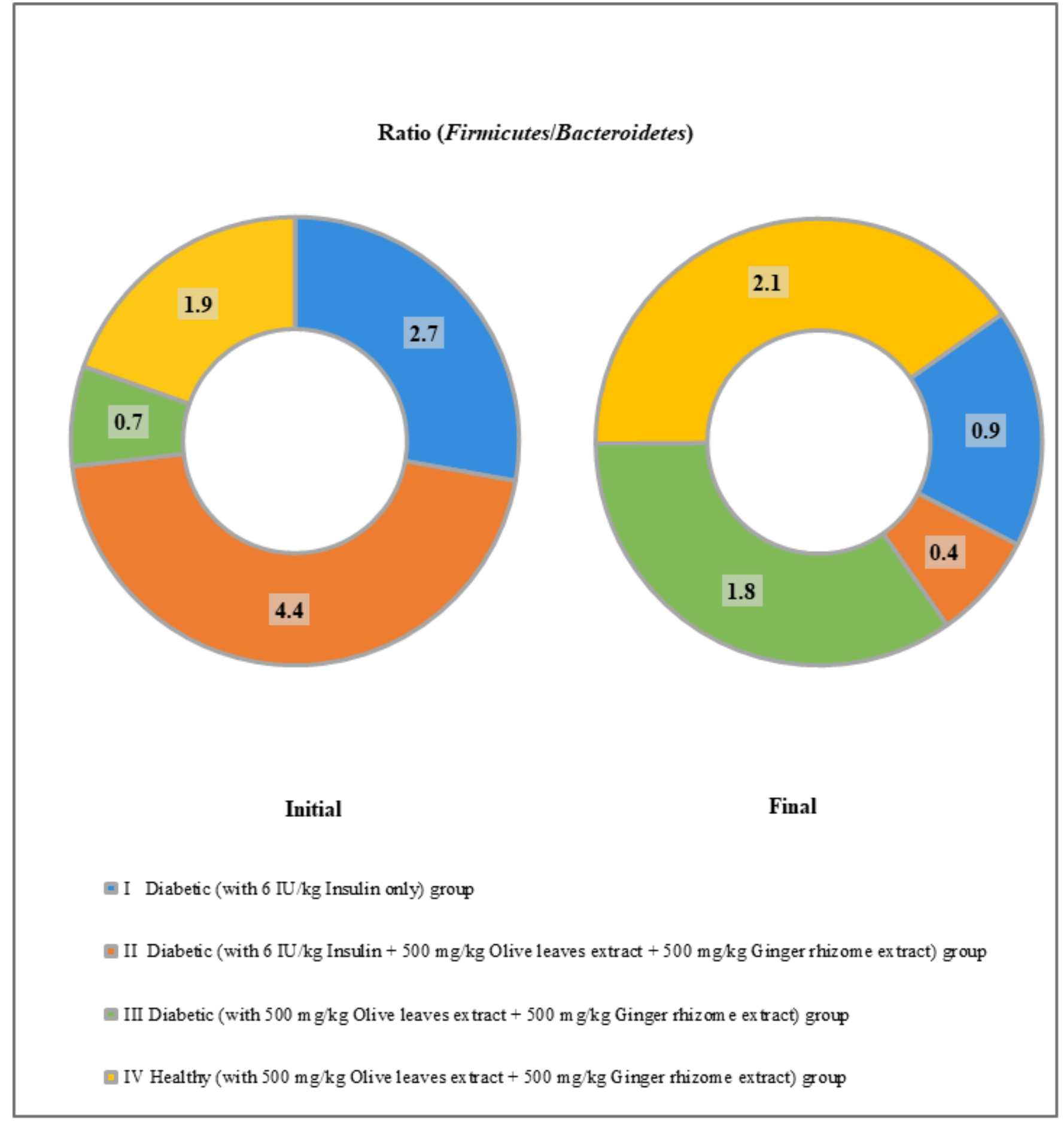

Figure 3. Ratio (Firmicutes/Bacteroidetes) in fecal samples. Samples of feces were freshly collected from day 0 before giving anything (Initial), and the fecal samples were collected again from the same rats after the first week of treatment (Final).

Bacteroidetes (including Prevotella and Bacteroides genera) showed a more marked change than that of other predominant genera after 1 week of treatment administration. An increased relative abundance of gut microbiota Lactobacillus was observed in groups I and IV, while a decrease in Clostridium was detected in groups II and IV, regardless of administering insulin or not. On the other hand, an increased relative abundance in Prevotella was detected in all groups, except group III. A deceased relative abundance of Bacteroides was detected only in group IV (Fig. 4).

\section{DISCUSSION}

Type 1 diabetes (T1D) is a chronic autoimmune disease, clinically characterized by damaging the insulin-producing cells in the pancreas. For 75 years, the number of T1D cases has increased 


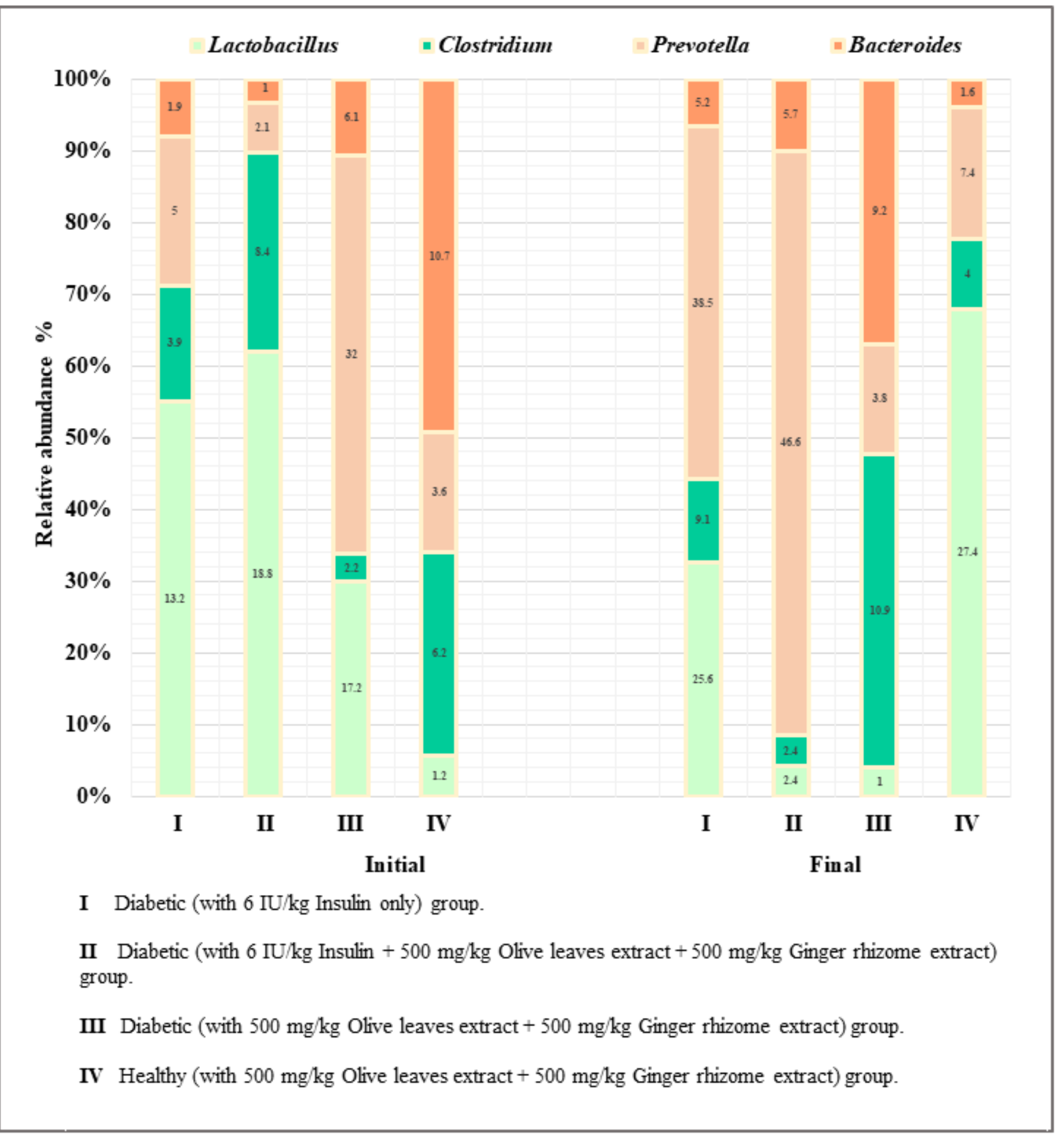

Figure 4. Relative abundance of the most abundant genera in fecal samples. Samples of feces were freshly collected from day 0 before giving anything (Initial), and the fecal samples were collected again from the same rats after the first week of treatment (Final).

rapidly in many countries around the world. Several studies have put forward that this is not due to genes alone, but also due to changes in the environment and lifestyle. These factors have led to a distribution of gut microbiota (Knip and Siljander, 2016). A gut microbiota imbalance may be the cause of, or may lead to, the development of diabetes (Carrera-Quintanar et al., 2018). Today, polyphenols compounds that are found naturally in plants have received great attention as one approach that could change gut microbiota from pathogenic to beneficial (Shabbir et al., 2021). In this study, the polyphenol-rich combined aqueous extract of olive leaves and ginger rhizome was investigated for its effect on the gut microbiota of alloxan-induced rat models.

Alloxan-induced diabetes animal models have been commonly used in diabetes in vivo researches. Studies have 
shown that alloxan-diabetic rats are hyperglycemic due to damage to the insulin-secreting cells of the pancreas (Arun and Nalini, 2002). Many studies have indicated that alloxan changes the gut microbiota community in alloxan-diabetic rats (Dey, 2019).

In the present study, 1 week following various treatments to the rat groups led to increased biodiversity microbiota for all groups, excepts group I, which received the insulin alone. This result can be explained based on data from previous studies, which have shown that the intraperitoneal alloxan treatment causes a reduction in the gut microbial diversity in diabetic rats relative to nondiabetic controls (Dey, 2019). Consequently, the extract with or without insulin in this study can demonstrably fight the reducing effect of alloxan on the gut microbiota biodiversity in diabetic rats. Moreover, it has a positive effect on the gut microbiota biodiversity in healthy rats. However, insulin alone has a negative effect on the gut microbiota biodiversity in diabetic rats. Many studies have suggested that a decreased bacterial biodiversity in children might contribute to disease progression autoantibody positivity to clinical T1D (Knip and Siljander, 2016). Therefore, the extract may play an important role in slowing down or preventing T1D progression through its positive effect on the gut microbiota biodiversity. Furthermore, it can be administered alongside insulin, as it has been shown to prevent the negative effects of insulin on the gut microbiota biodiversity of diabetic rats.

The extract alone without insulin led to elevating the Firmicutes/Bacteroidetes ratio in both healthy and diabetic rats; however, the insulin with or without this extract led to reducing the phyla ratio in the other two diabetic groups, therefore suggesting a negative effect of insulin on the phyla ratio. Based on the diabetic studies at the phyla levels, previous data indicated that the decreased Firmicutes/Bacteroidetes ratio was observed in T1D (Li et al., 2019). Moreover, the Firmicutes/Bacteroidetes ratio has a significantly negative correlation with the plasma glucose level (Zhang et al., 2015), and dietary interventions that improved T1D have caused an increased Firmicutes/Bacteroidetes ratio (Chen et al., 2017).

Recent studies have demonstrated that the change of gut microbiota by lower diversity and resilience plays an important role in the initiation and development of DM (Li et al., 2019; Wang et al., 2017). Moreover, natural compounds, such as polyphenols, are vital elements in regulating gut microbiota. Recently, several studies have shown that polyphenols have an antidiabetic effect by regulating gut microbiota composition and abundance (Li et al., 2019).

The induced change in gut microbiota after ingestion of the combined extract can be understood based on the biochemical effect of the individual extract's polyphenol constituents. The microbiota in the colon are responsible for the metabolism of around $95 \%$ of the undigested polyphenols from daily meals (Dueñas et al., 2015a). Thus, these compounds and their metabolites may modify gut microbiota through the promotion of the growth of beneficial bacteria and the inhibition of pathogenic bacteria (Dueñas et al., 2015a). Firmicutes and Bacteroidetes are the main phyla of the gut microbiota involved in the breakdown of undigested food residues like polyphenols (Zhang et al., 2015). The products of these residues are smaller metabolites, such as phenolic acids and short-chain fatty acid (SCFAs). The accumulation of the generated SCFAs leads to a drop in the $\mathrm{pH}$ from 6.5 to 5.5 . This acidic $\mathrm{pH}$ has a reflective effect on the colon microbiota that, on the one hand, suppress few genera of Gram-negative and, on the other hand, promote few genera of Gram-positive bacteria (Etxeberria et al., 2013). Around $95 \%$ of these SCFAs are mainly acetate, propionate, and butyrate, which can be rapidly absorbed in the colonic epithelial cells to provide several antidiabetic effects through many potential mechanisms. These mechanisms include altering the microbiota composition, stimulating the secretion of the gut hormone (glucagon-like peptide 1) that promotes satiety in the host, and reducing the systemic lipopolysaccharides and inflammation. To illustrate, improving the gut barrier function of SCFAs is vital for sufficient mucin synthesis, which is important for confirming tight junctions between epithelial cells. Mucin deficiency leads to increased intestinal permeability, which causes damage to pancreatic cells due to increased absorption of exogenous antigens (Aw and Fukuda, 2018; Ding et al., 2019; Greiner and Bäckhed, 2011; Larsen et al., 2010; Munro, 2016; Puddu et al., 2014; Tremaroli and Bäckhed, 2012).

Studies into the link between diabetes and gut microbiota suggest that the microbes belonging to the phylum Firmicutes (including Lactobacillus), as well as other microorganisms belonging to the phylum Bacteroidetes (including Prevotella), significantly decreased in T1D (Zhang et al., 2015). On the contrary, other microorganisms belonging to the phylum Firmicutes (including Clostridium) and the microorganisms belonging to the phylum Bacteroidetes (including Bacteroides) significantly increased in the T1D group (Zhang et al., 2015). All these observations have been noted in the diabetic group, which was treated with the combined aqueous extract alone in this study. To illustrate, Lactobacillus and Prevotella decreased and Clostridium and Bacteroides increased after one week of the combined aqueous extract administration to the diabetic group. This shows that the combination without insulin in this study does not possess the ability to shift gut microbiota towards normal balance in diabetic rats on the genera levels.

Although $6 \mathrm{IU} / \mathrm{kg}$ insulin only cannot fight the elevating relative abundances of Clostridium and Bacteroides, it was able to increase the amount of Lactobacillus and Prevotella in diabetic rats. Treatment of the diabetic group with insulin and the combined extract together led to an increase in Prevotella and a decrease in Clostridium. The combination of aqueous extracts given orally with subcutaneous insulin induced a decrease in the Clostridium levels more effectively than insulin alone. Unfortunately, there is insufficient information regarding the effect of subcutaneous insulin and this combination on gut microbiota in the literature. Therefore, further studies should be conducted to clarify this.

The most remarkable results in this work have been noted in the healthy group. The combination of the aqueous extracts of olive leaves and ginger rhizome shifted the four most important genera, and the change was beneficial. The combination increased the amounts of Lactobacillus and Prevotella and decreased the amounts of Clostridium and Bacteroides. It is well documented that the genera Prevotella and Lactobacillus are responsible for digesting fibers and polysaccharides and producing SCFAs (Alkanani et al., 2015). An increase in 
Prevotella has been observed in a diet with high plant fibers, which is common among African children with grain-rich diets (Alkanani et al., 2015).

Furthermore, Žugčić et al., (2019) reported that Lactobacillus converts oleuropein to hydroxytyrosol. Accordingly, Žugčić et al., (2019) mentioned that olive leaf extracts may have a beneficial role in promoting and flourishing probiotic bacteria, such as Lactobacillus during this hydrolysis process.

However, an increase in proteolytic Bacteroides bacteria has been associated with the "Western diet," which is characterized by being high in protein and fat contents, along with reduced plant fiber (Alkanani et al., 2015). Bacteroides appear to be the main contributor to microbiome dysbiosis both before the development of autoimmunity and after T1D diagnosis (Davis-Richardson and Triplett, 2015). Moreover, the Mediterranean diet, which is high in fiber with low levels of red meat, leads to decreases in Clostridium (Singh et al., 2017). Many species of the genus Clostridium are undesirable bacteria that can produce harmful products (lipopolysaccharide) that are associated with immunerelated disorders (Dueñas et al., 2015a). Additionally, Žugčić et al. (2019) reported that olive leaf extracts may have a beneficial role in inhibiting harmful bacteria such as Clostridium.

In conclusion, the combined aqueous extract of olive leaves and ginger rhizome has a powerful positive effect on the Firmicutes/Bacteroidetes ratio in both healthy and diabetic rats. This combination also decreases harmful Clostridium in insulin-treated diabetic rats. Additionally, the combined aqueous extract has the most notable results in the healthy group, in which it increased the amounts of Lactobacillus and Prevotella and decreased the amounts of Clostridium and Bacteroides. In order to apply these results, which were obtained from the crude extractions on humans, more research is still needed. The required research should focus on two main lines: (i) identifying the active compounds in the extractions and (ii) conducting a similar study on diabetic patients.

\section{ACKNOWLEDGMENTS}

The authors would like to thank the efforts of Mr. Salem Al-shawabekeh, Supervisor of the Animal House at ASU.

\section{CONFLICTS OF INTEREST}

The authors have declared that no conflicts of interest exist

\section{PUBLISHER NOTE}

This journal remains neutral with regard to jurisdictional claims in published institutional affiliation.

\section{REFERENCES}

Abdulrazaq NB, Cho MM, Win NN, Zaman R, Rahman MT. Beneficial effects of ginger (Zingiber officinale) on carbohydrate metabolism in streptozotocin-induced diabetic rats. Br J Nutr, 2012; 108(7):1194-201.

Abu-Zaiton A, Abu-Albasal M. Water decoction of olive leaf reduces blood glucose in normal and alloxan diabetic rats. Int Conf Med Biol Pharm Sci, 2012; (130040):17-9.

Afify AEMMRA, El-Beltagi HS, Fayed SA, El-Ansary AE. Beneficial and potent effect of olive leaves extract on hyperglycemic state, kidney and liver function in STZ-induced type 2 diabetes mellitus. Fresenius Environ Bull, 2018; 27(5A):3733-9.
Alkanani AK, Hara N, Gottlieb PA, Ir D, Robertson CE, Wagner BD, Frank DN, Zipris D. Alterations in intestinal microbiota correlate with susceptibility to type 1 diabetes. Diabetes, 2015; 64(10):3510-20.

Aluwong T, Ayo JO, Kpukple A, Oladipo OO. Amelioration of hyperglycaemia, oxidative stress and dyslipidaemia in alloxan-induced diabetic Wistar rats treated with probiotic and vitamin C. Nutrients, 2016; 1-15.

Arun N, Nalini N. Efficacy of turmeric on blood sugar and polyol pathway in diabetic albino rats. Plant Foods Hum Nutr, 2002; 57(1):41-52. Aw W, Fukuda S. Understanding the role of the gut ecosystem in diabetes mellitus. J Diabetes Investig, 2018; 9(1):5-12.

Baynest HW. Classification, pathophysiology, diagnosis and management of diabetes mellitus. J Diabetes Metab, 2015; 06(05):1-9.

Bi X, Lim J, Henry CJ. Spices in the management of diabetes mellitus. Food Chem, 2017; 217:281-93.

Butt MS, Sultan MT. Ginger and its health claims: molecular aspects. Crit Rev Food Sci Nutr, 2011; 51(5):383-93.

Carrera-Quintanar L, Roa RIL, Quintero-Fabián S, SánchezSánchez MA, Vizmanos B, Ortuño-Sahagún D. Phytochemicals that influence gut microbiota as prophylactics and for the treatment of obesity and inflammatory diseases. Mediators Inflamm, 2018; 2018:9734845.

Chaudhury A, Duvoor C, Shekhawat NS, Sasapu A, Mirza W, Lohani GP, Montales MT, Chada A, Musham CK, Reddy Dendi VS, Kraleti S, Marco A, Patil N, Chaudhury A, Ravilla R, Beebe A, Kuriakose K. Clinical review of antidiabetic drugs: implications for type 2 diabetes mellitus management. Front Endocrinol (Lausanne), 2017;8(1):6.

Chen K, Chen H, Faas MM, de Haan BJ, Li J, Xiao P, Zhang H, Diana J, de Vos P, Sun J. Specific inulin-type fructan fibers protect against autoimmune diabetes by modulating gut immunity, barrier function, and microbiota homeostasis. Mol Nutr Food Res, 2017; 61(8):1-35.

Chodak A. The inhibitory effect of polyphenols on human gut microbiota. J Physiol Pharmacol, 2012; (14):497-503.

Davis-Richardson AG, Triplett EW. A model for the role of gut bacteria in the development of autoimmunity for type 1 diabetes. Diabetologia, 2015; 58(7):1386-93.

Dey P. Gut microbiota in phytopharmacology: a comprehensive overview of concepts, reciprocal interactions, biotransformations and mode of actions. Pharmacol Res, 2019; 147(5):104367.

Ding Q, Zhang B, Zheng W, Chen X, Zhang J, Yan R, Zhang T, Yu L, Dong Y, Ma B. Liupao tea extract alleviates diabetes mellitus and modulates gut microbiota in rats induced by streptozotocin and high-fat, high-sugar diet. Biomed Pharmacother, 2019; 118(July):1-7.

Djurasevic S, Bojic S, Nikolic B, Dimkic I, Todorovic Z, Djordjevic J, Mitic-Culafic D. Beneficial effect of virgin coconut oil on alloxan-induced diabetes and microbiota composition in rats. Plant Foods Hum Nutr, 2018; 73(4):295-301.

Dueñas M, Cueva C, Muñoz-González I, Jiménez-Girón A, Sánchez-Patán F, Santos-Buelga C, Moreno-Arribas MV, Bartolomé B. Studies on modulation of gut microbiota by wine polyphenols: from isolated cultures to omic approaches. Antioxidants, 2015a; 4(1):1-21.

Dueñas M, González I, Cueva C, Girón A, Patán F, Buelga C, Arribas MV, Bartolomé B. A survey of modulation of gut microbiota by dietary polyphenols. Biomed Res Int, 2015b; 2015:850902.

Embuscado ME. Spices and herbs: natural sources of antioxidants - a mini-review. J Funct Foods, 2015; 18:811-9.

Etxeberria U, Fernández-Quintela A, Milagro FI, Aguirre L, Martínez JA, Portillo MP. Impact of polyphenols and polyphenol-rich dietary sources on gut microbiota composition. J Agric Food Chem, 2013; 61(40):9517-33.

Ghanbari R, Anwar F, Alkharfy KM, Gilani AH, Saari N Valuable nutrients and functional bioactives in different parts of olive (Olea europaea L.)-a review. Int J Mol Sci, 2012; 13:3291-340.

Greiner T, Bäckhed F. Effects of the gut microbiota on obesity and glucose homeostasis. Trends Endocrinol Metab, 2011; 22(4):117-23.

Jacob B, Narendhirakannan RT. Role of medicinal plants in the management of diabetes mellitus: a review. 3 Biotech, 2019; 9(1):1-7. 
Knip M, Siljander H. The role of the intestinal microbiota in type 1 diabetes mellitus. Nat Rev Endocrinol, 2016; 12(3):154-67.

Kumbhare MR, Sivakumar T. Caesalpinia pulcherrima extracts on blood glucose in normal and alloxan monohydrate-induced diabetic rats. J Biol Sci, 2019; 19(1):34-9.

Larsen N, Vogensen FK, Van Den Berg FWJ, Nielsen DS, Andreasen AS, Pedersen BK, Al-Soud WA, Sørensen SJ, Hansen LH, Jakobsen M. Gut microbiota in human adults with type 2 diabetes differs from non-diabetic adults. PLoS One, 2010; 5(2):e9085.

Li BY, Xu XY, Gan RY, Sun QC, Meng JM, Shang A, Mao QQ, Li H Bin. Targeting gut microbiota for the prevention and management of diabetes mellitus by dietary natural products. Foods, 2019;8(10):440.

Munro N. Gut microbiota: its role in diabetes and obesity. Diabetes Prim Care, 2016; 18(4):1-6.

Özcan MM, Matthäus B. A review: benefit and bioactive properties of olive (Olea europaea L.) leaves. Eur Food Res Technol, 2017; 243(1):89-99.

Puddu A, Sanguineti R, Montecucco F, Viviani GL. Evidence for the gut microbiota short-chain fatty acids as key pathophysiological molecules improving diabetes. Mediators Inflamm, 2014; 2014:162021.

Queipo-Ortuno MI, Boto-Ordonez M, Murri M, GomezZumaquero JM, Clemente-Postigo M, Estruch R, Diaz FC, Andres-Lacueva $\mathrm{C}$, Tinahones FJ. Influence of red wine polyphenols and ethanol on the gut microbiota. Am J Clin Nutr, 2012; 95(2):1323-34.

Shabbir U, Rubab M, Daliri EBM, Chelliah R, Javed A, Oh DH. Curcumin, quercetin, catechins and metabolic diseases:the role of gut microbiota. Nutrients, 2021; 13:206

Singh RK, Chang HW, Yan D, Lee KM, Ucmak D, Wong K, Abrouk M, Farahnik B, Nakamura M, Zhu TH, Bhutani T, Liao W. Influence of diet on the gut microbiome and implications for human health. J Transl Med, 2017; 15(1):1-17.

Tremaroli V, Bäckhed F. Functional interactions between the gut microbiota and host metabolism. Nature, 2012; 489(7415):242-9.

Wang B, Yao M, Lv L, Ling Z, Li L. The human microbiota in health and disease. Engineering, 2017; 3(1):71-82.

Weiss M, Steiner D, Philipson L. Insulin biosynthesis, secretion, structure, and structure-activity relationships. Endotext. MDText.com, Inc., South Dartmouth, MA, 2000.

Yaribeygi H, Farrokhi FR, Butler AE, Sahebkar A, Mather KJ, Lteif A, Steinberg HO, Baron AD, Ünal D, da Rocha Fernandes JD, Cho NH, Ogurtsova K, Linnenkamp U, Shaw JJE, Guariguata L, Makaroff LE, Cavan D, Huang Y, Lauritzen T, Jørgensen ME, Færch K, Pedersen O, Vistisen D, Torekov SS, Johansen NB, Witte DR, Hansen T, Pacini G, Holst JJ, Ahrén B, Jonsson A, Rodrigues MA, Gomes DA, Andrade VA, Leite MF, Nathanson MH, Ahmad SI, Zaccardi F, Webb DR, Yates T, Davies MJ, ReP, A. J, Kangralkar VA, Patil SD, Bandivadekar RM, Park MK, Jung U, Roh C, Karuranga S, Cho NH, Ohlrogge AW, Shaw JJE, da Rocha Fernandes JD,
Huang Y, Malanda B, Gómez de la Cámara A, Lapetra J, Castell C, MarínIbañez A, García JM, Elosua R, Gavrila D, Segura A, Cabré JJ, Grau M, Berjón J, Quesada M, Mata M, Guembe MJ, Moreno-Iribas C, Subirana I, Pavone NC, Rigo F, Marrugat J, Basora J, Ramos R, Baena-Díez JM, LoraPablos D, Frances A, Mayoral E, Tormo-Díaz MJ, Franch J, Barricarte A, Frontera G, García-Lareo M, Medrano MJ, Peñafiel J, Nichols G, Zhang X, Zhang P, Shaw JJE, Brown J, Vistisen D, Sicree R, Duvoor C, Shekhawat NS, Sasapu A, Mirza W, Lohani GP, Montales MT, Chada A, Musham CK, Reddy Dendi VS, Kraleti S, Marco A, Patil N, Chaudhury A, Ravilla R, Beebe A, Kuriakose K, Ceriello A. IDF Diabetes Atlas: global estimates of diabetes prevalence for 2017 and projections for 2045. Diabetes Res Clin Pract, 2016; 39(11):1987-95.

Zhang B, Sun W, Yu N, Sun J, Yu X, Li X, Xing Y, Yan D, Ding Q, Xiu Z, Ma B, Yu L, Dong Y. Anti-diabetic effect of baicalein is associated with the modulation of gut microbiota in streptozotocin and high-fat-diet induced diabetic rats. J Funct Foods, 2018; 46(2):256-67.

Zhang YJ, Li S, Gan RY, Zhou T, Xu DP, Li H Bin. Impacts of gut bacteria on human health and diseases. Int J Mol Sci, 2015; 16(4):7493-519.

Zoair MA. A possible antioxidanteffect of olive leaf extraction in diabetic rats. Glob J Sci Res, 2014; 2(6):165-70.

Žugčić T, Abdelkebir R, Alcantara C, Collado MC, GarcíaPérez JV, Meléndez-Martínez AJ, Režek Jambrak A, Lorenzo JM, Barba FJ. From extraction of valuable compounds to health promoting benefits of olive leaves through bioaccessibility, bioavailability and impact on gut microbiota. Trends Food Sci Technol, 2019; 83:63-77.

How to cite this article:

Alshaer S, El-Hajji FD, Abu-Tayeh R, Basheti I, Al-Najjar MAA. Changes in gut microbiota of alloxan-induced diabetic rats in response to orally administered combined aqueous extracts of olive leaves and ginger. J Appl Pharm Sci, 2022; 12(03):150-159. 